OPEN ACCESS

Edited by:

Liwu Fu,

Sun Yat-Sen University, China

Reviewed by:

Stefano Fais,

National Institute of Health (ISS), Italy

Sabarish Ramachandran,

Texas Tech University Health Sciences

Center, United States

*Correspondence:

Chune Yu

yuchune0125@163.com

Mingqing $X u$

xumingqing0018@163.com

Specialty section:

This article was submitted to Molecular and Cellular Oncology,

a section of the journal

Frontiers in Oncology

Received: 09 March 2021

Accepted: 16 June 2021

Published: 28 June 2021

Citation:

Zheng X, Yu C and Xu M (2021) Linking

Tumor Microenvironment to Plasticity of Cancer Stem Cells: Mechanisms and Application in Cancer Therapy.

Front. Oncol. 11:678333.

doi: 10.3389/fonc.2021.678333

\section{Linking Tumor Microenvironment to Plasticity of Cancer Stem Cells: Mechanisms and Application in Cancer Therapy}

\author{
Xiaobo Zheng ${ }^{1,2}$, Chune $\mathrm{Yu}^{2 *}$ and Mingqing $\mathrm{Xu}{ }^{1,3^{*}}$ \\ 1 Department of Liver Surgery, West China Hospital, Sichuan University, Chengdu, China, ${ }^{2}$ Laboratory of Tumor Targeted \\ and Immune Therapy, Clinical Research Center for Breast, State Key Laboratory of Biotherapy, West China Hospital, Sichuan \\ University, Chengdu, China, ${ }^{3}$ Department of Hepatopancreatobiliary Surgery, Meishan City People's Hospital, Meishan \\ Hospital of West China Hospital, Sichuan University, Meishan, China
}

Cancer stem cells (CSCs) are a minority subset of cancer cells that can drive tumor initiation, promote tumor progression, and induce drug resistance. CSCs are difficult to eliminate by conventional therapies and eventually mediate tumor relapse and metastasis. Moreover, recent studies have shown that CSCs display plasticity that renders them to alter their phenotype and function. Consequently, the varied phenotypes result in varied tumorigenesis, dissemination, and drug-resistance potential, thereby adding to the complexity of tumor heterogeneity and further challenging clinical management of cancers. In recent years, tumor microenvironment (TME) has become a hotspot in cancer research owing to its successful application in clinical tumor immunotherapy. Notably, emerging evidence shows that the TME is involved in regulating CSC plasticity. TME can activate stemness pathways and promote immune escape through cytokines and exosomes secreted by immune cells or stromal cells, thereby inducing non-CSCs to acquire CSC properties and increasing CSC plasticity. However, the relationship between TME and plasticity of CSCs remains poorly understood. In this review, we discuss the emerging investigations on TME and CSC plasticity to illustrate the underlying mechanisms and potential implications in suppressing cancer progression and drug resistance. We consider that this review can help develop novel therapeutic strategies by taking into account the interlink between TME and CSC plasticity.

Keywords: cancer stem cell, plasticity, tumor microenvironment, cancer progression, resistance 


\section{INTRODUCTION}

Cancer stem cells (CSCs) are a unique subpopulation of cancer cells that possess self-renewal and differentiation abilities. CSC differentiation enhances the aggressiveness of tumors, thereby aggravating cancer progression (1). CSCs are essential for intratumoral heterogeneity and are responsible for tumor relapse, metastasis, and therapeutic resistance. Moreover, these cells are difficult to eliminate by conventional therapies, rendering additional challenges in cancer management (2). Recently, emerging evidence shows that CSCs can present different phenotypes that render diverse functions with varying degrees of mediating tumorigenesis and progression (3), which is attributed to plasticity of CSCs. Notably, CSC plasticity hinders successful cancer therapies, and it is indeed a pivotal area of research to better understand CSC dynamics and thereby the subsequent development of efficient targeting therapies (4). Although CSCs display a high level of plasticity, how they dynamically transit between non-CSC and CSC states or among varied phenotypes of CSC subsets, and what are the molecular mechanisms underlying these dynamic processes remain poorly understood (5-7). Recently, tumor microenvironment (TME) has been identified as a promising target for cancer therapy, owing to its successful application in clinical tumor immunotherapy. Interestingly, an emerging role of the TME in remodeling CSC plasticity has been observed; the CSC niche is critical in regulating CSC plasticity (8). Within this niche, various cell types, including immune cells, mesenchymal stem cells (MSCs), cancer-associated fibroblasts (CAFs), and exosomes derived from live cells, in addition to the physical and chemical composition of the microenvironment, play roles in maintaining and promoting phenotypic transition of CSCs by secreting factors or providing an immunosuppressive environment (9). In this review, we comprehensively discuss the recent advances with respect to the interaction between TME and CSC plasticity and illustrate the underlying molecular mechanisms. Further, this overview can help provide new insights into the existing therapeutic approaches and designing potential strategies for cancer therapy.

\section{EMERGENCE OF PLASTICITY OF CSCs}

Cellular plasticity is the ability of cells to differentiate into multiple lineages, which occurs not only during embryonic development but throughout life (10-12). Although plasticity is a highly regulated process under physiological conditions, cancer cells can utilize this adaptive ability for their survival and progression (13). Recently, several studies have demonstrated that CSCs exhibit varied states and can transition between states dynamically during cancer progression, corroborating CSC plasticity (14-16). Chaffer et al. observed that non-CSCs could

Abbreviations: CAFs, cancer associated fibroblasts; CRC, colorectal cancer; CSCs, cancer stem cells; EMT, epithelial-mesenchymal transition; MSCs, mesenchymal stem cells; TME, tumor microenvironment; TNBC, triple negative breast cancer; VM, vasculogenic mimicry. spontaneously transit to CSC-like phenotype in vitro and in vivo in breast cancer cells; this transition was regulated by ZEB1, a key regulator of the epithelial-mesenchymal transition (EMT) (17). Further, Dirkse et al. reported that the well-accepted CSC markers, such as CD133, A2B5, SSEA, and CD15, are not uniformly expressed among glioblastoma cells. Most of the cancer cells adapt a plastic state in response to stimuli in the TME (18). Conclusively, they proposed that CSC plasticity is an adaptation of the cancer cells to the extracellular pressure in the TME, which includes chemical signals, hypoxia-induced physical pressure, or inflammatory environment. In melanoma, JARID1B, a marker of melanoma stem-like cells, was dynamically regulated, indicating the dynamic nature of CSCs (19). Colorectal cancer (CRC), a classical disease model to study CSCs, showed compelling evidence of CSC plasticity during tumor evolution. LGR5, a characteristic marker of CRC stem cells, was expressed in human colon cancer cell lines developed by Kobayashi et al., confirming CSC properties in the established cell lines (20). On treating one of these cell lines with an anticancer drug, they observed transition from $\mathrm{LGR}^{+}$to LGR5 state, while withdrawal of the drug resulted in the cells reverting to the LGR5 ${ }^{+}$state, indicating the inherent plasticity of CSCs. Interestingly, there are two contradictory opinions on the effect of CSC plasticity on inducing liver metastases: one is that CSC plasticity is primarily associated with tumorigenesis and not cancer metastasis (21), whereas the other considers that a majority of CRC metastases are seeded by CSCs (22). The controversy indicates that the non-CSC-to-CSC transition and plasticity of CSCs are crucial for both primary tumor and metastatic growth. Reportedly, vasculogenic mimicry (VM), a hallmark process of cancer cell switch by which cancer cells transdifferentiate and acquire endothelial cell-like properties, accompanies CSC plasticity (23). Zhang et al. revealed that in renal cell carcinoma, high expression of the CSC markers CD133 and CD44 and VM correlated with poor survival (24). Taken together, CSC plasticity mediates interconversion of CSC subsets, as well as gives rise to non-CSC (differentiated) cells.

\section{PLASTICITY OF CSCs CONTRIBUTES TO TUMOR HETEROGENEITY}

Tumor heterogeneity in cancer biology is widely investigated for efficient clinical management of cancers (25-27). Intrinsic intratumoral heterogeneity and acquired diversification under therapy endow some tumor cells to gain aggressiveness, rendering their survival and emergence of resistance to therapy. These properties are the driving forces for the development of therapy-resistant populations that ultimately result in relapse and metastasis $(28,29)$. The origin of intratumoral heterogeneity in tumor cells has been widely considered to be resulting from two controversial explanations: clonal evolution and the CSC model $(30,31)$. In 1976, Peter Nowell first proposed the theory of clonal evolution for tumor heterogeneity, suggesting that step-wise clonal selection is essential for introducing mutations in tumor genes. In this 
process, a new tumor is derived from a single cell, and poorer tumor outcomes result from multistep mutations, allowing the selection of more aggressive subclones in the derived clonal population. He hypothesized that in the main effective subclone, cells may acquire identical tumorigenic abilities (32). On the contrary, the CSC hypothesis proposes that only a small portion of the tumor subclone have tumorigenic potential and self-renewal ability $(31,33-36)$. CSCs can differentiate into nonCSCs that develop into a bulk of tumor mass, in a fashion similar to that of stem cell development (37). In 2001, Reya et al. proposed that there exists a minority of subclones with stem cell traits in the tumor tissue, with self-renewal and pluripotent differentiation potential (38). Currently, CSCs have been isolated from more than 10 tumor types, including breast and lung cancers, CRC, melanoma, and glioma (39-42). The origin of tumor cells remains vaguely understood, and tumor heterogeneity augments the difficulties encountered in tumor therapy. Tumor heterogeneity exists objectively, as supported by the fact that some cells are tumorigenic, while others are not (4346). Therefore, questions over the origin of tumorigenic cells and whether they are CSCs or normal cells still prevail. One opinion is that tumorigenic cells emerge either from stem/progenitor cells or normal somatic cells that acquire mitotic ability (26). Clonal evolution and the CSC model are not necessarily mutually exclusive. Notably, CSC plasticity enhances complexity of intratumoral heterogeneity. However, the question whether CSCs are tumor-initiating cells or primary tumor cells remains to be clarified. The fact that CSCs can change phenotypes via different programs, such as dynamic epithelial/mesenchymal status, has led to the speculation that non-CSCs can transform back to CSCs (47-49). Therefore, CSC plasticity can be presumed as the cell state capable of being shaped by EMT, wherein this process can allow interconversion of CSCs and nonCSCs (50-53).

\section{INFLUENCE OF TME ON CSC PLASTICITY}

For many years, the emphasis of tumor therapy has been on the tumor cells themselves, with a focus on inhibiting their innate ability to adhere and migrate. However, in recent years many studies have shown that tumor cells and peritumor cells (the tumor niche) closely communicate through signaling pathways (54-56). Cells in the tumor niche (such as fibroblasts and immune cells) or cytokines secreted by these cells are accomplices in tumor metastasis and chemoresistance (57). Tumorigenesis and metastasis are closely related to the TME (54), where the niche is not only involved in tissue function, structure, and metabolism but also related to the intracellular milieu of tumor cells (58). The TME can alter the conductions such that they are conducive for tumor growth, survival, and development through autocrine or paracrine secretion (58). Local tissues or distant sites can in turn limit and influence tumorigenesis as well as tumor growth and development through metabolism, secretion, immunity, and structural and functional changes. Both the tumor and the surrounding environment are interdependent and mutually promoting as well as not antagonizing each other. Further, characteristics of the TME, such as immunocyte and mesenchymal cell populations, exosomes, hypoxia, low $\mathrm{pH}$, nutritional deficiencies, and angiogenesis, are key to tumor formation and progression $(59,60)$.

Emerging evidence suggests that the immunocytes, a critical component in the TME, can regulate phenotypic plasticity of CSCs (61-63). Macrophages, an important cell type involved in complex regulating networks in the TME, are crucial in regulating CSC plasticity. Rao et al. emphasized the mutual influence and interactions between macrophages and CSCs. They reported that CD44 overexpressed by CSCs could induce the macrophages in the TME to secrete the cytokine osteopontin that can in turn bind to CD44 on the surface of tumor cells, thereby promoting tumor cell subclone formation (64). Moreover, analysis of clinical samples showed that osteopontin and CD44 correlated with the survival rate of patients with colon cancer. Additionally, macrophages can secrete oncostatin-M, a pleiotropic cytokine belonging to the IL-6 family, during chemotherapy. Oncostatin- $M$ in turn can activate the dedifferentiation of non-CSCs into aggressive CSCs in triple negative breast cancer (TNBC) (65). Similarly, interplay between macrophage polarization and CSC plasticity can alter the status of cancer cells in terms of EMT, thereby modulating plasticity of stemness in the TME (66). Reportedly, the stem cell factor LIN28, identified in ovarian CSCs, correlates with tumor growth and prognosis of ovarian cancer (67). Using advanced gene sequencing technology, LIN28 and the signaling molecule bone morphogenic protein-4, secreted by macrophages, were observed to be mutually regulated.

CAFs are a predominant component in the TME and play an important role in regulating CSC plasticity $(68,69)$. CAFs can modulate CSC plasticity through the IGF-II/IGF1R signaling pathway in lung cancer (70); FAK signaling in pancreatic adenocarcinoma (71); and c-Met/FRA1/HEY1 signaling in hepatocellular carcinoma (72). Normal non-cancerous fibroblasts embedded in the TME, upon exposure to chemotherapeutic drugs, undergo DNA damage and secrete a series of cytokines that stimulate cancer growth. Reportedly, the proteoglycan decorin, secreted by fibroblasts, inhibits tumor growth and can induce the expression of tumor-suppressor genes in the microenvironment surrounding TNBC, thereby restraining tumor metastasis (73). GATA3 can also inhibit cancer metastasis and is aberrantly expressed or deleted in most patients with breast cancer (74). Moreover, GATA3 can activate the downstream molecule miR-29b that can further inhibit the synthesis of proteins required for tumor metastasis. In the absence of GATA3, the metastasis of cancer cells cannot be stopped, and metastatic tumor cells can induce inflammatory responses, stimulate angiogenesis, and acquire nutrients for metastasis. Nakasone et al. observed increased sensitivity of breast cancer cells to drugs in mice after the selective deletion of two distinct types of TME factors, MMP9 and CCR2 (75). Moreover, treatment with HGF or combinatorial inhibition of RAF and MET can be used as potential therapeutic 
strategies in $B R A F$-mutant melanoma. MSCs, which are mature progenitor cells, are essential components of the TME and considered to assist in metastasis (76). Following contact with MSCs, breast cancer cells activate lysyl oxidase expression that can enhance their metastatic ability and promote primary tumor dissemination to the lungs and bones. In a recent study, NOTCH1 signaling activated by MSC-derived dermal fibroblasts was observed to regulate plasticity and stemness of melanoma stem/initiating cells (77). This finding suggests that CAF-targeted strategies may aid in efficiently eradicating CSCs.

Recent studies have shown that exosomes derived from tumor cells or non-tumor cells are prominent messengers in regulating CSC plasticity $(78,79)$. For instance, exosomes secreted from CAF contribute to CSC proliferation and induce chemoresistance in colorectal cancer (80). Exosomes also play an important role in tumor metastasis through the premetastatic niche formation $(81,82)$. Exosomes secreted by stromal cells within the TME facilitate the transformation of non-CSCs into CSCs (83). Hu et al. demonstrated that CAF-derived exosomes significantly promote clonogenicity and increase the percentage of colorectal CSCs by activating the WNT pathway (80). Furthermore, exosomes can regenerate stem cell phenotypes by regulating the stem cell-related signaling pathways, including the Notch pathway, Wnt pathway, and Hedgehog pathway (84). In addition, exosomes derived from CSCs promote the proliferation and metastasis of clear cell renal cell carcinoma by transporting miR-19b-3p (85). Colorectal CSC-derived exosomes also facilitate tumorigenesis through mediating neutrophils (86).

The physical and chemical composition of the CSC niche, such as hypoxia and acidity, can also contribute to the regulation of CSC plasticity $(87,88)$. It is known that hypoxia modulates various aspects of cancer development and progression, including CSC plasticity. Reportedly, hypoxia could increase the plasticity of CSCs in glioblastoma by upregulating important molecules related to stem cell pathways, such as OCT4, NANOG, and c-MYC (89). The hypoxic niche can also determine the fate of CSCs in vivo. Tumor cells in the hypoxic niche show enhanced CSC properties compared to those in the non-hypoxic niche, which is attributed to activation of the ROS/ HIF-1 $\alpha / c-$ Met pathway (90). Similarly, tumor-derived acidosis can also promote the invasion and metastasis of tumor cells via metabolic reprogramming (91). Furthermore, the acidic TME can facilitate immune invasion by inhibiting the activation of effector T cells and inducing M2 macrophage polarization (91, 92). Estrella et al. found that survival of CSCs depends on low $\mathrm{pH}$ environments that promote autophagy (93). Furthermore, Spugnini et al. demonstrated that a highly acidic TME can lead to chemoresistance, and targeted proton pumps with inhibitors can improve anti-tumor responses (94). Additionally, accumulating evidence demonstrated that the release of exosomes is significantly improved in an acidic TME, thereby leading to malignant tumor phenotypes (95-97). Collectively, CSCs are the key players in tumor recurrence and metastasis, wherein the TME provides conditions favorable for the growth of CSCs.

\section{THERAPEUTIC STRATEGIES ENCOMPASSING PLASTICITY AND NICHE OF CSCS}

Intratumoral heterogeneity and complexity of the TME are the major challenges in effective cancer treatment. CSC plasticity augments tumor heterogeneity, further enhancing and rendering difficulty in regulating drug resistance, relapse, and metastasis (98). Although chemotherapeutics can eliminate most tumor cells, a minority of CSCs and resistant cancer cells tend to escape the lethal effect of these drugs, eventually rendering tumor recurrence (1). It is even more difficult to completely eradicate CSCs with plasticity. Anticancer drugs normally only target tumor cells within their cell cycle; as plasticity of CSCs varies between the stationary and dynamic states, they are not affected, which is the primary reason for treatment failure (99). Consequently, CSC plasticity is now recognized as a major "target cell population" in oncology (4). Recent studies have shown that therapies targeting both plasticity and niche of CSCs may be promising strategies in suppressing tumor progression. For example, CAFs could activate stem cell pathways and are highly abundant in the TME. Targeting the relevant CAF-CSC signaling axis should therefore eliminate CSCs via induced differentiation and/or promoted apoptosis, contributing to tumor regression. Recently, a neutralizing monoclonal antibody against GPR77 was observed to effectively control tumor formation and reverse chemoresistance by eliminating $\mathrm{CD} 0^{+} \mathrm{GPR} 7^{+}$subpopulation of CAFs, proposing a CAFtargeted therapeutic strategy (100). Another research reported that CCL2 mediates a crosstalk between cancer cells and stromal fibroblasts that regulates breast CSCs. CCL2 secreted by CAFs activates the NOTCH1 pathway that further induces CSC phenotype in the breast cancer cells, granting them selfrenewal potential, indicating CCL2 as a potential target to block non-CSC-to-CSC switch (101). Luo et al. observed that co-inhibition of glycolysis and thioredoxin and glutathione antioxidant pathways suppresses tumor-initiating potential, tumor growth, and metastasis of breast cancer cells under metabolic stress or hypoxia. The probable reason is that the combination strategy eliminates both quiescent mesenchymallike and proliferative epithelial-like states of breast CSCs (102). Further, programmed cell death protein 1 blockade, combined with a granulocyte-macrophage colony-stimulating factormodified CSC vaccine, was observed to enhance a specific antitumor immunotherapy response against bladder cancer (103). Exosomes, hypoxia, and acidity are indeed pivotal for CSC-niche development, and molecules capable of targeting exosomes or acidity or inducing hypoxia are potential therapeutic regimens for eliminating CSCs by reprograming the TME.

CSCs can gain or lose stemness and switch their status by adapting to the physical conditions (hypoxia and acidity), and communicate with stroma and immune cells, corroborating the crosstalk between intrinsic CSC plasticity and niche complexity. Therefore, combination strategies that target CSC plasticity together with immunotherapy or TME-modulating agents 
could be promising in inhibiting tumor progression and metastasis. However, whether CSC plasticity arises as a consequence of the microenvironment-exerted selection pressure or whether it is an intrinsic, default feature of cancer cells that enables them to adapt to varying conditions of the TME remains poorly unknown. Although most cancer cell subpopulations are capable of phenotypic transition, they vary in their speed and ability of adaptation. Recent studies on glioblastoma suggest that the intrinsic plasticity of tumor cells renders them to randomly switch between different phenotypes (defined by varied expression of CSC markers) and adapt to the TME $(18,104)$. In summary, these studies underscore that alterations in the CSC niche play important roles in restraining plasticity of CSCs and highlight the need to better understand the crosstalk between TME and CSC plasticity. Collectively, targeting CSCs and their niches is a promising strategy for efficient cancer therapy.

\section{CONCLUSIONS}

In this review, we present the recent advances in oncology that relate TME and CSC plasticity. All the observations pinpoint to the fact that developing novel CSC plasticity-suppressing strategies by targeting TME can improve cancer prognosis and patient survival. Therefore, we propose that exploiting the intrinsic dependence of CSCs to interact with non-tumor cell types in the CSC niche is a potential strategy for cancer therapy. The need-of-the-hour is, therefore, to understand the fundamental mechanisms underlying CSC plasticity and to illustrate the effect of the dynamic properties of CSCs; these

\section{REFERENCES}

1. Nassar D, Blanpain C. Cancer Stem Cells: Basic Concepts and Therapeutic Implications. Annu Rev Pathol (2016) 11:47-76. doi: 10.1146/annurevpathol-012615-044438

2. Vlashi E, Pajonk F. Cancer Stem Cells, Cancer Cell Plasticity and Radiation Therapy. Semin Cancer Biol (2015) 31:28-35. doi: 10.1016/ j.semcancer.2014.07.001

3. Shimokawa M, Ohta Y, Nishikori S, Matano M, Takano A, Fujii M, et al. Visualization and Targeting of LGR5(+) Human Colon Cancer Stem Cells. Nature (2017) 545(7653):187-92. doi: 10.1038/nature22081

4. Cazet AS, Hui MN, Elsworth BL, Wu SZ, Roden D, Chan C-L, et al. Targeting Stromal Remodeling and Cancer Stem Cell Plasticity Overcomes Chemoresistance in Triple Negative Breast Cancer. Nat Commun (2018) 9 (1):2897. doi: 10.1038/s41467-018-05220-6

5. Ahmed N, Escalona R, Leung D, Chan E, Kannourakis G. Tumour Microenvironment and Metabolic Plasticity in Cancer and Cancer Stem Cells: Perspectives on Metabolic and Immune Regulatory Signatures in Chemoresistant Ovarian Cancer Stem Cells. Semin Cancer Biol (2018) 53:265-81. doi: 10.1016/j.semcancer.2018.10.002

6. Takebe N, Miele L, Harris PJ, Jeong W, Bando H, Kahn M, et al. Targeting Notch, Hedgehog, and Wnt Pathways in Cancer Stem Cells: Clinical Update. Nat Rev Clin Oncol (2015) 12(8):445-64. doi: 10.1038/nrclinonc.2015.61

7. Sancho P, Burgos-Ramos E, Tavera A, Bou Kheir T, Jagust P, Schoenhals M, et al. MYC/PGC-1 $\alpha$ Balance Determines the Metabolic Phenotype and Plasticity of Pancreatic Cancer Stem Cells. Cell Metab (2015) 22(4):590-605. doi: 10.1016/j.cmet.2015.08.015 aspects can subsequently help improve clinical management of cancers. Further investigation on the interactions of CSC plasticity, tumor, and TME, particularly clarifying the associated signaling pathways, will greatly facilitate our understanding of the invasive and metastatic features of malignant tumors. Regarding application in clinical treatment, combination TME-targeted therapy with the molecular drugs that reverse or block CSC plasticity should be envisaged to provide new insights into effectively inhibiting tumor metastases and efficiently managing cancer. Finally, this combination therapy can be applied in neoadjuvant chemotherapy and postsurgical resection, to help eradicate residual, dormant, and distantly located CSCs, potentially preventing distant metastases.

\section{AUTHOR CONTRIBUTIONS}

MX proposed and supervised the research. XZ and CY collected the references. XZ, and CY drafted the paper. All authors contributed to the article and approved the submitted version.

\section{FUNDING}

This study was supported by grants from the National Natural Science Foundation of China (No. 81803574), China Postdoctoral Science Foundation (2019M653430), Post-Doctor Research Project, West China Hospital, Sichuan University (2018HXBH003), and Key Technology Research and Development Program of the Sichuan Province (2019YFS0208, 2021YFSY0009).

8. Plaks V, Kong N, Werb Z. The Cancer Stem Cell Niche: How Essential Is the Niche in Regulating Stemness of Tumor Cells? Cell Stem Cell (2015) 16 (3):225-38. doi: 10.1016/j.stem.2015.02.015

9. Sung P-J, Rama N, Imbach J, Fiore S, Ducarouge B, Neves D, et al. CancerAssociated Fibroblasts Produce Netrin-1 to Control Cancer Cell Plasticity. Cancer Res (2019) 79(14):3651-61. doi: 10.1158/00085472.CAN-18-2952

10. Marjanovic ND, Hofree M, Chan JE, Canner D, Wu K, Trakala M, et al. Emergence of a High-Plasticity Cell State During Lung Cancer Evolution. Cancer Cell (2020) 38(2):229-46.e13. doi: 10.1016/j.ccell.2020.06.012

11. Shenoy S. Cell Plasticity in Cancer: A Complex Interplay of Genetic, Epigenetic Mechanisms and Tumor Micro-Environment. Surg Oncol (2020) 34:154-62. doi: 10.1016/j.suronc.2020.04.017

12. Basova L, Parfitt GJ, Richardson A, Delcroix V, Umazume T, Pelaez D, et al. Origin and Lineage Plasticity of Endogenous Lacrimal Gland Epithelial Stem/Progenitor Cells. iScience (2020) 23(6):101230. doi: 10.1016/ j.isci.2020.101230

13. Kong D, Hughes CJ, Ford HL. Cellular Plasticity in Breast Cancer Progression and Therapy. Front Mol Biosci (2020) 7:72. doi: 10.3389/ fmolb.2020.00072

14. Thankamony AP, Saxena K, Murali R, Jolly MK, Nair R. Cancer Stem Cell Plasticity - a Deadly Deal. Front Mol Biosci (2020) 7:79. doi: 10.3389/ fmolb.2020.00079

15. Christin JR, Wang C, Chung CY, Liu Y, Dravis C, Tang W, et al. Stem Cell Determinant SOX9 Promotes Lineage Plasticity and Progression in BasalLike Breast Cancer. Cell Rep (2020) 31(10):107742. doi: 10.1016/ j.celrep.2020.107742 
16. Das PK, Pillai S, Rakib MA, Khanam JA, Gopalan V, Lam AKY, et al. Plasticity of Cancer Stem Cell: Origin and Role in Disease Progression and Therapy Resistance. Stem Cell Rev Rep (2020) 16(2):397-412. doi: 10.1007/ s12015-019-09942-y

17. Chaffer CL, Marjanovic ND, Lee T, Bell G, Kleer CG, Reinhardt F, et al. Poised Chromatin at the ZEB1 Promoter Enables Breast Cancer Cell Plasticity and Enhances Tumorigenicity. Cell (2013) 154(1):61-74. doi: 10.1016/j.cell.2013.06.005

18. Dirkse A, Golebiewska A, Buder T, Nazarov PV, Muller A, Poovathingal S, et al. Stem Cell-Associated Heterogeneity in Glioblastoma Results From Intrinsic Tumor Plasticity Shaped by the Microenvironment. Nat Commun (2019) 10(1):1787. doi: 10.1038/s41467-019-09853-z

19. Roesch A, Fukunaga-Kalabis M, Schmidt EC, Zabierowski SE, Brafford PA, Vultur A, et al. A Temporarily Distinct Subpopulation of Slow-Cycling Melanoma Cells is Required for Continuous Tumor Growth. Cell (2010) 141 (4):583-94. doi: 10.1016/j.cell.2010.04.020

20. Kobayashi S, Yamada-Okabe H, Suzuki M, Natori O, Kato A, Matsubara K, et al. LGR5-Positive Colon Cancer Stem Cells Interconvert With DrugResistant LGR5-Negative Cells and Are Capable of Tumor Reconstitution. Stem Cells (2012) 30(12):2631-44. doi: 10.1002/stem.1257

21. de Sousa e Melo F, Kurtova AV, Harnoss JM, Kljavin N, Hoeck JD, Hung J, et al. A Distinct Role for Lgr5 Stem Cells in Primary and Metastatic Colon Cancer. Nature (2017) 543(7647):676-80. doi: 10.1038/nature21713

22. Fumagalli A, Oost KC, Kester L, Morgner J, Bornes L, Bruens L, et al. Plasticity of Lgr5-Negative Cancer Cells Drives Metastasis in Colorectal Cancer. Cell Stem Cell (2020) 26(4):569-78. doi: 10.1016/ j.stem.2020.02.008

23. Fernández-Cortés M, Delgado-Bellido D, Oliver FJ. Vasculogenic Mimicry: Become an Endothelial Cell "But Not So Much". Front Oncol (2019) 9:803. doi: 10.3389/fonc.2019.00803

24. Zhang Y, Sun B, Zhao X, Liu Z, Wang X, Yao X, et al. Clinical Significances and Prognostic Value of Cancer Stem-Like Cells Markers and Vasculogenic Mimicry in Renal Cell Carcinoma. J Surg Oncol (2013) 108(6):414-9. doi: $10.1002 /$ jso. 23402

25. Marusyk A, Janiszewska M, Polyak K. Intratumor Heterogeneity: The Rosetta Stone of Therapy Resistance. Cancer Cell (2020) 37(4):471-84. doi: $10.1016 /$ j.ccell.2020.03.007

26. Hausser J, Alon U. Tumour Heterogeneity and the Evolutionary Trade-Offs of Cancer. Nat Rev Cancer (2020) 20(4):247-57. doi: 10.1038/s41568-0200241-6

27. Kinker GS, Greenwald AC, Tal R, Orlova Z, Cuoco MS, McFarland JM, et al. Pan-Cancer Single-Cell RNA-Seq Identifies Recurring Programs of Cellular Heterogeneity. Nat Genet (2020) 52(11):1208-18. doi: 10.1038/s41588-02000726-6

28. Lawson ARJ, Abascal F, Coorens THH, Hooks Y, O’Neill L, Latimer C, et al. Extensive Heterogeneity in Somatic Mutation and Selection in the Human Bladder. Sci (New York NY) (2020) 370(6512):75-82. doi: 10.1126/ science.aba8347

29. Persi E, Wolf YI, Horn D, Ruppin E, Demichelis F, Gatenby RA, et al. Mutation-Selection Balance and Compensatory Mechanisms in Tumour Evolution. Nat Rev Genet (2020) 22(4):251-62. doi: 10.1038/s41576-02000299-4

30. Shackleton M, Quintana E, Fearon ER, Morrison SJ. Heterogeneity in Cancer: Cancer Stem Cells Versus Clonal Evolution. Cell (2009) 138 (5):822-9. doi: 10.1016/j.cell.2009.08.017

31. Prasetyanti PR, Medema JP. Intra-Tumor Heterogeneity From a Cancer Stem Cell Perspective. Mol Cancer (2017) 16(1):41. doi: 10.1186/s12943-0170600-4

32. Nowell PC. The Clonal Evolution of Tumor Cell Populations. Science (1976) 194(4260):23-8. doi: 10.1126/science.959840

33. Magee JA, Piskounova E, Morrison SJ. Cancer Stem Cells: Impact, Heterogeneity, and Uncertainty. Cancer Cell (2012) 21(3):283-96. doi: 10.1016/j.ccr.2012.03.003

34. Rich JN. Cancer Stem Cells: Understanding Tumor Hierarchy and Heterogeneity. Medicine (2016) 95(1 Suppl 1):S2-7. doi: 10.1097/md.0000000000004764

35. Clara JA, Monge C, Yang Y, Takebe N. Targeting Signalling Pathways and the Immune Microenvironment of Cancer Stem Cells - a Clinical Update. Nat Rev Clin Oncol (2020) 17(4):204-32. doi: 10.1038/s41571-019-0293-2
36. Butti R, Gunasekaran VP, Kumar TVS, Banerjee P, Kundu GC. Breast Cancer Stem Cells: Biology and Therapeutic Implications. Int J Biochem Cell Biol (2019) 107:38-52. doi: 10.1016/j.biocel.2018.12.001

37. Walcher L, Kistenmacher AK, Suo H, Kitte R, Dluczek S, Strauß A, et al Cancer Stem Cells-Origins and Biomarkers: Perspectives for Targeted Personalized Therapies. Front Immunol (2020) 11:1280. doi: 10.3389/ fimmu. 2020.01280

38. Reya T, Morrison SJ, Clarke MF, Weissman IL. Stem Cells, Cancer, and Cancer Stem Cells. Nature (2001) 414(6859):105-11. doi: 10.1038/35102167

39. Meyer MJ, Fleming JM, Lin AF, Hussnain SA, Ginsburg E, Vonderhaar BK CD44posCD49fhiCD133/2hi Defines Xenograft-Initiating Cells in Estrogen Receptor-Negative Breast Cancer. Cancer Res (2010) 70(11):4624-33. doi: 10.1158/0008-5472.can-09-3619

40. Boiko AD, Razorenova OV, van de Rijn M, Swetter SM, Johnson DL, Ly DP et al. Human Melanoma-Initiating Cells Express Neural Crest Nerve Growth Factor Receptor CD271. Nature (2010) 466(7302):133-7. doi: 10.1038/ nature09161

41. Wu Y, Zhang J, Zhang X, Zhou H, Liu G, Li Q. Cancer Stem Cells: A Potential Breakthrough in HCC-Targeted Therapy. Front Pharmacol (2020) 11:198. doi: 10.3389/fphar.2020.00198

42. Osman A, Afify SM, Hassan G, Fu X, Seno A, Seno M. Revisiting Cancer Stem Cells as the Origin of Cancer-Associated Cells in the Tumor Microenvironment: A Hypothetical View From the Potential of Ipscs. Cancers (2020) 12(4):879. doi: 10.3390/cancers12040879

43. McGranahan N, Swanton C. Clonal Heterogeneity and Tumor Evolution: Past, Present, and the Future. Cell (2017) 168(4):613-28. doi: 10.1016/ j.cell.2017.01.018

44. Dagogo-Jack I, Shaw AT. Tumour Heterogeneity and Resistance to Cancer Therapies. Nat Rev Clin Oncol (2018) 15(2):81-94. doi: 10.1038/ nrclinonc.2017.166

45. Cros J, Raffenne J, Couvelard A, Poté N. Tumor Heterogeneity in Pancreatic Adenocarcinoma. Pathobiol: J immunopathol Mol Cell Biol (2018) 85(12):64-71. doi: 10.1159/000477773

46. Lawson DA, Kessenbrock K, Davis RT, Pervolarakis N, Werb Z. Tumour Heterogeneity and Metastasis at Single-Cell Resolution. Nat Cell Biol (2018) 20(12):1349-60. doi: 10.1038/s41556-018-0236-7

47. Celià-Terrassa T, Jolly MK. Cancer Stem Cells and Epithelial-toMesenchymal Transition in Cancer Metastasis. Cold Spring Harbor Perspect Med (2020) 10(7):a036905. doi: 10.1101/cshperspect.a036905

48. Lu W, Kang Y. Epithelial-Mesenchymal Plasticity in Cancer Progression and Metastasis. Dev Cell (2019) 49(3):361-74. doi: 10.1016/j.devcel.2019.04.010

49. Yang J, Antin P, Berx G, Blanpain C, Brabletz T, Bronner M, et al. Guidelines and Definitions for Research on Epithelial-Mesenchymal Transition. Nat Rev Mol Cell Biol (2020) 21(6):341-52. doi: 10.1038/s41580-020-0237-9

50. Beerling E, Seinstra D, de Wit E, Kester L, van der Velden D, Maynard C, et al. Plasticity Between Epithelial and Mesenchymal States Unlinks EMT From Metastasis-Enhancing Stem Cell Capacity. Cell Rep (2016) 14 (10):2281-8. doi: 10.1016/j.celrep.2016.02.034

51. da Silva-Diz V, Lorenzo-Sanz L, Bernat-Peguera A, Lopez-Cerda M, Muñoz P. Cancer Cell Plasticity: Impact on Tumor Progression and Therapy Response. Semin Cancer Biol (2018) 53:48-58. doi: 10.1016/ j.semcancer.2018.08.009

52. Gupta PB, Pastushenko I, Skibinski A, Blanpain C, Kuperwasser C. Phenotypic Plasticity: Driver of Cancer Initiation, Progression, and Therapy Resistance. Cell Stem Cell (2019) 24(1):65-78. doi: 10.1016/ j.stem.2018.11.011

53. Zheng X, Dai F, Feng L, Zou H, Feng L, Xu M. Communication Between Epithelial-Mesenchymal Plasticity and Cancer Stem Cells: New Insights Into Cancer Progression. Front Oncol (2021) 11:617597. doi: 10.3389/ fonc.2021.617597

54. Wu T, Dai Y. Tumor Microenvironment and Therapeutic Response. Cancer Lett (2017) 387:61-8. doi: 10.1016/j.canlet.2016.01.043

55. Locy H, de Mey S, de Mey W, De Ridder M, Thielemans K, Maenhout SK. Immunomodulation of the Tumor Microenvironment: Turn Foe Into Friend. Front Immunol (2018) 9:2909. doi: 10.3389/fimmu.2018.02909

56. Vitale I, Manic G, Coussens LM, Kroemer G, Galluzzi L. Macrophages and Metabolism in the Tumor Microenvironment. Cell Metab (2019) 30(1):3650. doi: 10.1016/j.cmet.2019.06.001 
57. Dougan M, Dougan SK. Targeting Immunotherapy to the Tumor Microenvironment. J Cell Biochem (2017) 118(10):3049-54. doi: 10.1002/ jcb. 26005

58. Hinshaw DC, Shevde LA. The Tumor Microenvironment Innately Modulates Cancer Progression. Cancer Res (2019) 79(18):4557-66. doi: 10.1158/0008-5472.can-18-3962

59. Noman MZ, Hasmim M, Lequeux A, Xiao M, Duhem C, Chouaib S, et al. Improving Cancer Immunotherapy by Targeting the Hypoxic Tumor Microenvironment: New Opportunities and Challenges. Cells (2019) 8 (9):1083. doi: 10.3390/cells8091083

60. Zhou F, Feng B, Yu H, Wang D, Wang T, Ma Y, et al. Tumor Microenvironment-Activatable Prodrug Vesicles for Nanoenabled Cancer Chemoimmunotherapy Combining Immunogenic Cell Death Induction and CD47 Blockade. Advanced materials (Deerfield Beach Fla) (2019) 31 (14):e1805888. doi: 10.1002/adma.201805888

61. Prager BC, Xie Q, Bao S, Rich JN. Cancer Stem Cells: The Architects of the Tumor Ecosystem. Cell Stem Cell (2019) 24(1):41-53. doi: 10.1016/ j.stem.2018.12.009

62. Bocci F, Gearhart-Serna L, Boareto M, Ribeiro M, Ben-Jacob E, Devi GR, et al. Toward Understanding Cancer Stem Cell Heterogeneity in the Tumor Microenvironment. Proc Natl Acad Sci U S A (2019) 116(1):148-57. doi: $10.1073 /$ pnas. 1815345116

63. Nazio F, Bordi M, Cianfanelli V, Locatelli F, Cecconi F. Autophagy and Cancer Stem Cells: Molecular Mechanisms and Therapeutic Applications. Cell Death Differ (2019) 26(4):690-702. doi: 10.1038/s41418-019-0292-y

64. Rao G, Wang H, Li B, Huang L, Xue D, Wang X, et al. Reciprocal Interactions Between Tumor-Associated Macrophages and CD44-Positive Cancer Cells via Osteopontin/CD44 Promote Tumorigenicity in Colorectal Cancer. Clin Cancer Res (2013) 19(4):785-97. doi: 10.1158/1078-0432.ccr$12-2788$

65. Doherty MR, Parvani JG, Tamagno I, Junk DJ, Bryson BL, Cheon HJ, et al. The Opposing Effects of Interferon-Beta and Oncostatin-M as Regulators of Cancer Stem Cell Plasticity in Triple-Negative Breast Cancer. Breast Cancer research: BCR (2019) 21(1):54. doi: 10.1186/s13058019-1136-x

66. Li X, Jolly MK, George JT, Pienta KJ, Levine H. Computational Modeling of the Crosstalk Between Macrophage Polarization and Tumor Cell Plasticity in the Tumor Microenvironment. Front Oncol (2019) 9:10. doi: 10.3389/ fonc. 2019.00010

67. Ma W, Ma J, Xu J, Qiao C, Branscum A, Cardenas A, et al. Lin28 Regulates BMP 4 and Functions With Oct4 to Affect Ovarian Tumor Microenvironment. Cell Cycle (2013) 12(1):88-97. doi: 10.4161/cc.23028

68. Su S, Chen J, Yao H, Liu J, Yu S, Lao L, et al. CD10(+)GPR77(+) CancerAssociated Fibroblasts Promote Cancer Formation and Chemoresistance by Sustaining Cancer Stemness. Cell (2018) 172(4):841-56.e16. doi: 10.1016/ j.cell.2018.01.009

69. Huang TX, Guan XY, Fu L. Therapeutic Targeting of the Crosstalk Between Cancer-Associated Fibroblasts and Cancer Stem Cells. Am J Cancer Res (2019) 9(9):1889-904.

70. Chen W-J, Ho C-C, Chang Y-L, Chen H-Y, Lin C-A, Ling T-Y, et al. CancerAssociated Fibroblasts Regulate the Plasticity of Lung Cancer Stemness via Paracrine Signalling. Nat Commun (2014) 5:3472. doi: 10.1038/ ncomms 4472

71. Begum A, McMillan RH, Chang Y-T, Penchev VR, Rajeshkumar NV, Maitra A, et al. Direct Interactions With Cancer-Associated Fibroblasts Lead to Enhanced Pancreatic Cancer Stem Cell Function. Pancreas (2019) 48 (3):329-34. doi: 10.1097/MPA.0000000000001249

72. Lau EYT, Lo J, Cheng BYL, Ma MKF, Lee JMF, Ng JKY, et al. CancerAssociated Fibroblasts Regulate Tumor-Initiating Cell Plasticity in Hepatocellular Carcinoma Through C-Met/FRA1/HEY1 Signaling. Cell Rep (2016) 15(6):1175-89. doi: 10.1016/j.celrep.2016.04.019

73. Buraschi S, Neill T, Owens RT, Iniguez LA, Purkins G, Vadigepalli R, et al. Decorin Protein Core Affects the Global Gene Expression Profile of the Tumor Microenvironment in a Triple-Negative Orthotopic Breast Carcinoma Xenograft Model. PLoS One (2012) 7(9):e45559. doi: 10.1371/ journal.pone.0045559

74. Chou J, Lin JH, Brenot A, Kim JW, Provot S, Werb Z. GATA3 Suppresses Metastasis and Modulates the Tumour Microenvironment by Regulating
microRNA-29b Expression. Nat Cell Biol (2013) 15(2):201-13. doi: 10.1038/ ncb2672

75. Nakasone ES, Askautrud HA, Kees T, Park J-H, Plaks V, Ewald AJ, et al. Imaging Tumor-Stroma Interactions During Chemotherapy Reveals Contributions of the Microenvironment to Resistance. Cancer Cell (2012) 21(4):488-503. doi: 10.1016/j.ccr.2012.02.017

76. El-Haibi CP, Bell GW, Zhang J, Collmann AY, Wood D, Scherber CM, et al. Critical Role for Lysyl Oxidase in Mesenchymal Stem Cell-Driven Breast Cancer Malignancy. Proc Natl Acad Sci U S A (2012) 109(43):17460-5. doi: 10.1073/pnas.1206653109

77. Du Y, Shao H, Moller M, Prokupets R, Tse YT, Liu Z-J. Intracellular Notch1 Signaling in Cancer-Associated Fibroblasts Dictates the Plasticity and Stemness of Melanoma Stem/Initiating Cells. Stem Cells (2019) 37(7):86575. doi: 10.1002/stem.3013

78. Spugnini EP, Logozzi M, Di Raimo R, Mizzoni D, Fais S. A Role of TumorReleased Exosomes in Paracrine Dissemination and Metastasis. Int J Mol Sci (2018) 19(12):3968. doi: 10.3390/ijms19123968

79. Sun Z, Wang L, Dong L, Wang X. Emerging Role of Exosome Signalling in Maintaining Cancer Stem Cell Dynamic Equilibrium. J Cell Mol Med (2018) 22(8):3719-28. doi: 10.1111/jcmm.13676

80. Hu Y, Yan C, Mu L, Huang K, Li X, Tao D, et al. Fibroblast-Derived Exosomes Contribute to Chemoresistance Through Priming Cancer Stem Cells in Colorectal Cancer. PLoS One (2015) 10(5):e0125625. doi: 10.1371/ journal.pone.0125625

81. Logozzi M, Spugnini E, Mizzoni D, Di Raimo R, Fais S. Extracellular Acidity and Increased Exosome Release as Key Phenotypes of Malignant Tumors. Cancer Metastasis Rev (2019) 38(1-2):93-101. doi: 10.1007/s10555-01909783-8

82. Zhao H, Achreja A, Iessi E, Logozzi M, Mizzoni D, Di Raimo R, et al. The Key Role of Extracellular Vesicles in the Metastatic Process. Biochim Biophys Acta Rev Cancer (2018) 1869(1):64-77. doi: 10.1016/j.bbcan.2017.11.005

83. Lugini L, Valtieri M, Federici C, Cecchetti S, Meschini S, Condello M, et al. Exosomes From Human Colorectal Cancer Induce a Tumor-Like Behavior in Colonic Mesenchymal Stromal Cells. Oncotarget (2016) 7(31):50086-98. doi: 10.18632/oncotarget.10574

84. Xu J, Liao K, Zhou W. Exosomes Regulate the Transformation of Cancer Cells in Cancer Stem Cell Homeostasis. Stem Cells Int (2018) 2018:4837370. doi: 10.1155/2018/4837370

85. Wang L, Yang G, Zhao D, Wang J, Bai Y, Peng Q, et al. CD103-Positive CSC Exosome Promotes EMT of Clear Cell Renal Cell Carcinoma: Role of Remote Mir-19b-3p. Mol Cancer (2019) 18(1):86. doi: 10.1186/s12943019-0997-z

86. Hwang WL, Lan HY, Cheng WC, Huang SC, Yang MH. Tumor Stem-Like Cell-Derived Exosomal RNAs Prime Neutrophils for Facilitating Tumorigenesis of Colon Cancer. J Hematol Oncol (2019) 12(1):10. doi: 10.1186/s13045-019-0699-4

87. Debele TA, Yu L-Y, Yang C-S, Shen Y-A, Lo C-L. pH- and GSH-Sensitive Hyaluronic Acid-MP Conjugate Micelles for Intracellular Delivery of Doxorubicin to Colon Cancer Cells and Cancer Stem Cells. Biomacromolecules (2018) 19(9):3725-37. doi: 10.1021/acs.biomac.8b00856

88. Peng F, Wang JH, Fan WJ, Meng YT, Li MM, Li TT, et al. Glycolysis Gatekeeper PDK1 Reprograms Breast Cancer Stem Cells Under Hypoxia. Oncogene (2018) 37(8):1062-74. doi: 10.1038/onc.2017.368

89. Srivastava C, Irshad K, Dikshit B, Chattopadhyay P, Sarkar C, Gupta DK, et al. FAT1 Modulates EMT and Stemness Genes Expression in Hypoxic Glioblastoma. Int J Cancer (2018) 142(4):805-12. doi: 10.1002/ijc.31092

90. Jung N, Kwon HJ, Jung HJ. Downregulation of Mitochondrial UQCRB Inhibits Cancer Stem Cell-Like Properties in Glioblastoma. Int J Oncol (2018) 52(1):241-51. doi: 10.3892/ijo.2017.4191

91. Pillai SR, Damaghi M, Marunaka Y, Spugnini EP, Fais S, Gillies RJ. Causes, Consequences, and Therapy of Tumors Acidosis. Cancer metastasis Rev (2019) 38(1-2):205-22. doi: 10.1007/s10555-019-09792-7

92. Calcinotto A, Filipazzi P, Grioni M, Iero M, De Milito A, Ricupito A, et al. Modulation of Microenvironment Acidity Reverses Anergy in Human and Murine Tumor-Infiltrating T Lymphocytes. Cancer Res (2012) 72(11):274656. doi: 10.1158/0008-5472.Can-11-1272

93. Estrella V, Chen T, Lloyd M, Wojtkowiak J, Cornnell HH, Ibrahim-Hashim A, et al. Acidity Generated by the Tumor Microenvironment Drives Local 
Invasion. Cancer Res (2013) 73(5):1524-35. doi: 10.1158/0008-5472.can-122796

94. Spugnini EP, Fais S. Drug Repurposing for Anticancer Therapies. A Lesson From Proton Pump Inhibitors. Expert Opin Ther patents (2020) 30(1):15-25. doi: 10.1080/13543776.2020.1704733

95. Logozzi M, Mizzoni D, Angelini DF, Di Raimo R, Falchi M, Battistini L, et al. Microenvironmental $\mathrm{Ph}$ and Exosome Levels Interplay in Human Cancer Cell Lines of Different Histotypes. Cancers (2018) 10(10):370. doi: 10.3390/ cancers 10100370

96. Parolini I, Federici C, Raggi C, Lugini L, Palleschi S, De Milito A, et al. Microenvironmental pH Is a Key Factor for Exosome Traffic in Tumor Cells. J Biol Chem (2009) 284(49):34211-22. doi: 10.1074/jbc.M109.041152

97. Logozzi M, Angelini DF, Iessi E, Mizzoni D, Di Raimo R, Federici C, et al. Increased PSA Expression on Prostate Cancer Exosomes in In Vitro Condition and in Cancer Patients. Cancer Lett (2017) 403:318-29. doi: 10.1016/j.canlet.2017.06.036

98. Batlle E, Clevers H. Cancer Stem Cells Revisited. Nat Med (2017) 23 (10):1124-34. doi: 10.1038/nm.4409

99. Zhan T, Ambrosi G, Wandmacher AM, Rauscher B, Betge J, Rindtorff N, et al. MEK Inhibitors Activate Wnt Signalling and Induce Stem Cell Plasticity in Colorectal Cancer. Nat Commun (2019) 10(1):2197. doi: 10.1038/s41467-019-09898-0

100. Su S, Chen J, Yao H, Liu J, Yu S, Lao L, et al. CD10GPR77 Cancer-Associated Fibroblasts Promote Cancer Formation and Chemoresistance by Sustaining Cancer Stemness. Cell (2018) 172(4):841-56. doi: 10.1016/j.cell.2018.01.009
101. Tsuyada A, Chow A, Wu J, Somlo G, Chu P, Loera S, et al. CCL2 Mediates Cross-Talk Between Cancer Cells and Stromal Fibroblasts That Regulates Breast Cancer Stem Cells. Cancer Res (2012) 72(11):2768-79. doi: 10.1158/ 0008-5472.CAN-11-3567

102. Luo M, Shang L, Brooks MD, Jiagge E, Zhu Y, Buschhaus JM, et al. Targeting Breast Cancer Stem Cell State Equilibrium Through Modulation of Redox Signaling. Cell Metab (2018) 28(1):69-86. doi: 10.1016/j.cmet.2018.06.006

103. Shi X, Zhang X, Li J, Mo L, Zhao H, Zhu Y, et al. PD-1 Blockade Enhances the Antitumor Efficacy of GM-CSF Surface-Modified Bladder Cancer Stem Cells Vaccine. Int J Cancer (2018) 142(10):2106-17. doi: 10.1002/ijc.31219

104. Liau BB, Sievers C, Donohue LK, Gillespie SM, Flavahan WA, Miller TE, et al. Adaptive Chromatin Remodeling Drives Glioblastoma Stem Cell Plasticity and Drug Tolerance. Cell Stem Cell (2017) 20(2):233-46.e7. doi: 10.1016/j.stem.2016.11.003

Conflict of Interest: The authors declare that the research was conducted in the absence of any commercial or financial relationships that could be construed as a potential conflict of interest.

Copyright $\odot 2021$ Zheng, Yu and Xu. This is an open-access article distributed under the terms of the Creative Commons Attribution License (CC BY). The use, distribution or reproduction in other forums is permitted, provided the original author(s) and the copyright owner(s) are credited and that the original publication in this journal is cited, in accordance with accepted academic practice. No use, distribution or reproduction is permitted which does not comply with these terms. 